\title{
Investigation of phase transformations of iron nanoparticles during thermal annealing
}

\author{
Dinara Tulebayeva ${ }^{1,2, *}$, Assel Yermekova ${ }^{1,2}$, Artem Kozlovskiy ${ }^{1,2}$, and Maxim Zdorovets ${ }^{1,2,3}$ \\ ${ }^{1}$ Institute of Nuclear Physics of Republic of Kazakhstan, Astana, Kazakhstan \\ ${ }^{2}$ L.N. Gumilyov Eurasian National University, Astana, Kazakhstan \\ ${ }^{3}$ Ural Federal University named after the First President of Russia B.N. Yeltsin, Yekaterinburg, \\ Russia
}

\begin{abstract}
Structural properties and phase composition of nanoparticles based on iron oxide were studied. Mossbauer spectroscopy, X-ray diffraction, and scanning electron microscopy were used for the analysis of phase transformations. According to XRD and Mossbauer spectroscopy data, an increase in the annealing temperature, as well as the subsequent phase transformations of magnetite into maghemite and then to hematite, indicate an improvement in the structure and a decrease in microdistortions in the lattice as a result of annealing defects and vacancies. According to Mossbauer spectroscopy data at temperatures above $400{ }^{\circ} \mathrm{C}$, the lines of characteristic $\mathrm{FeO}$, which are characteristic for disordered iron oxide, are observed, which also confirms the improvement of the crystal structure of nanoparticles.
\end{abstract}

\section{Introduction}

In recent years, magnetic nanoparticles of iron oxide are of great interest for the creation of new materials for engineering, ecology, and biomedicine [1-5]. The presence of a magnetic core in nanoparticles allows the creation of nanostructures with homogeneous switching fields, which ensure reproducibility of the results.

When metal nanoparticles are used, it is often necessary to heat them in an oxidizing or protective atmosphere to change the structural and magnetic properties. The main advantages of heat treatment are the following: reduction of internal stress arising during the production, increase of strength properties due to reduction in the number of defects and changes in the defective structure, the structure becomes more ordered and resistant to external influences. However, the duration of heat treatment in time can play a dual role in changing the conductive properties, since a long thermal annealing leads to an irreversible change in physical parameters.

In this connection, it is interesting to study the effect of heat treatment on structural and magnetic properties of $\mathrm{Fe}_{\mathrm{x}} \mathrm{O}_{\mathrm{y}}$ nanoparticles, as well as phase transformations that arise under the influence of temperature.

\footnotetext{
* Corresponding author: tulebaevadinara01@gmail.com
} 


\section{Method of experiment}

Nanoparticles based on iron oxide were obtained by chemical synthesis of a mixture of iron (II) and (III) chloride, and addition of ammonium hydroxide. This reaction for the formation of oxide nanoparticles can be represented as follows:

$$
\mathrm{FeCl}_{2}+2 \mathrm{FeCl}_{3}+8 \mathrm{NH}_{3} \cdot \mathrm{H}_{2} \mathrm{O} \rightarrow \mathrm{Fe}_{3} \mathrm{O}_{4}+8 \mathrm{NH}_{4} \mathrm{Cl}+4 \mathrm{H}_{2} \mathrm{O}
$$

$2 \mathrm{M} \mathrm{FeCl}_{2}$ was dissolved in $2 \mathrm{M} \mathrm{HCl}, 1 \mathrm{M} \mathrm{FeCl} 3$ in a molar ratio of $1: 2$. To the resulting solution, $50 \mathrm{ml}$ of $\mathrm{NH}_{4} \mathrm{OH}(0.7 \mathrm{M})$ was added dropwise through the funnel over a period of 5 to 10 minutes while stirring with a magnetic stirrer. After synthesis, the resulting samples were washed in an ultrasonic bath and dried at room temperature for 24 hours.

The structure and morphology of the obtained nanoparticles were studied using a Hitachi TM3030 scanning electron microscope (SEM) with the Bruker XFlash MIN SVE energy dispersive microanalysis (EDA) system at an accelerating voltage of $15 \mathrm{kV}$. X-ray diffraction analysis (XRD) was obtained on a D8 ADVANCE ECO diffractometer (Bruker, Germany) using $\mathrm{CuK} \alpha$ radiation. When the lines on the diffractogram were approximated by the necessary number of symmetric pseudo-Voigt functions, the width of the registered lines at half their height (FWHM) was measured, which allowed characterizing the perfection of the crystal structure and the degree of crystallinity. Pseudo-Voigt functions were used to approximate the profile of XR peaks at a diffractogram:

$$
\begin{aligned}
& P V\left(x, x_{0}, \eta, b_{L}, b_{G}, A\right)=A\left[(1-\eta) \cdot G\left(x, x_{0}, b_{G}\right)+\eta \cdot L\left(x, x_{0}, b_{L}\right)\right] \\
& G\left(x, x_{0}, b_{G}\right)=\exp \left[-\frac{\left(x-x_{0}\right)^{2}}{2 b_{G}^{2}}\right], \\
& L\left(x, x_{0}, b_{L}\right)=\frac{1}{1+\left(\frac{x-x_{0}}{b_{L}}\right)^{2}}
\end{aligned}
$$

where $x$ is the variable corresponding to the reflection angle $2 \theta ; x_{0}$ specifies the position of function maximum; $\eta$ is the specific fraction of the Lorentz function; $A$ is a normalizing factor; $b_{G}$ and $b_{L}$ are parameters of the Gaussian functions $G\left(x, x_{0}, b_{G}\right)$ and Lorentz $L\left(x, x_{0}\right.$, $\left.b_{L}\right)$. As a criterion for such a correspondence, the root-mean-square deviation can be used, the minimum value of which, with a variation of these parameters, corresponds to their optimal set:

$$
\sigma=\sqrt{\frac{\sum_{i}\left(P V\left(x, x_{0}, \eta, b_{L}, b_{G}, A\right)_{i}-I_{i}\right)^{2}}{n}}
$$

Where $\left(P V\left(x, x_{0}, \eta, b_{L}, b_{G}, A\right)_{i}\right.$ is the value of the pseudo-Voigt function, $I_{i}$ is the value of the experimental intensity, $i$ is the number of the reflex profile point, and $n$ is the number of points in the profile.

Thermal annealing was carried out in the temperature range from 100 to $800{ }^{\circ} \mathrm{C}$ for 60 min in an oxygen-containing medium in a muffle furnace Nabertherm LE 4/11 / r6.

The Mossbauer studies were carried out using a spectrometer MS1104Em operating in the mode of constant accelerations with a triangular shape of the Doppler velocity of the source relative to the absorber. The ${ }^{57} \mathrm{Co}$ nuclei in the $\mathrm{Rh}$ matrix acted as a source. For the processing and analysis of Mossbauer spectra, methods for reconstructing the distributions 
of hyperfine parameters of the Mossbauer spectrum were used, taking into account the a priori information about the object of research, implemented in the SpectrRelax program.

\section{Results and discussion}

The SEM images of the synthesized structures are spherical nanoparticles, the average particle size is $20-25 \mathrm{~nm}$. The appearance of the diffractogram indicates the scattering of Xrays on nanoobjects (low-intensity and broadened peaks). The deviation of the diffraction peaks from the symmetrical shape indicates the presence in the crystal structure of a large number of defects and microarrays that arise during the synthesis of nanostructures.

An increase in the annealing temperature leads to an increase in the average nanoparticle size from 20-25 $\mathrm{nm}$ for the initial nanoparticles and 100-115 nm for annealed nanoparticles at a temperature of $800{ }^{\circ} \mathrm{C}$. Table 1 shows the data of changes in the main characteristics of the crystal structure obtained according to X-ray diffraction data.

Table 1. X-ray diffraction data.

\begin{tabular}{|c|c|c|c|c|c|c|}
\hline $\mathrm{T},{ }^{\circ} \mathrm{C}$ & $\begin{array}{l}\text { Structure } \\
\text { type }\end{array}$ & Phase & $\begin{array}{l}\text { Spatial } \\
\text { group }\end{array}$ & $\begin{array}{l}\text { Cell } \\
\text { parameter, } \AA\end{array}$ & $\begin{array}{l}\text { Crystalline size, } \\
\mathrm{nm}\end{array}$ & $\begin{array}{l}\text { Degree of } \\
\text { crystallinity, } \\
\%\end{array}$ \\
\hline Initial & \multirow[t]{5}{*}{ Cubic } & $\begin{array}{r}\mathrm{Fe}_{3} \mathrm{O}_{4} \\
\text { Magnetite }\end{array}$ & $\begin{array}{c}\text { Fd- } \\
3 \mathrm{~m}(227)\end{array}$ & $\mathrm{a}=8.3471(2)$ & 12.4 & 23 \\
\hline 100 & & $\begin{array}{c}\mathrm{Fe}_{3} \mathrm{O}_{4} \\
\text { Magnetite } \\
+ \\
\mathrm{Fe}_{2} \mathrm{O}_{3} \\
\end{array}$ & $\begin{array}{l}\quad \text { Fd- } \\
3 \mathrm{~m}(227) \\
+\quad \mathrm{Ia}- \\
3(206)\end{array}$ & $\begin{array}{l}a=8.3750(2)+ \\
a=9.4280(1)\end{array}$ & 12.5 & 27 \\
\hline 200 & & \multirow{3}{*}{$\begin{array}{l}\mathrm{Fe}_{2.12} \mathrm{O}_{3.19} \\
\text { Maghemite }\end{array}$} & \multirow{3}{*}{$\begin{array}{c}\text { P43 } \\
32(122)\end{array}$} & $\mathrm{a}=8.2988(2)$ & 13.2 & 34 \\
\hline 300 & & & & $\mathrm{a}=8.3315(2)$ & 15.6 & 38 \\
\hline 400 & & & & $\mathrm{a}=8.3412(2)$ & 16.7 & 46 \\
\hline 500 & \multirow[t]{4}{*}{$\begin{array}{l}\text { Rhombo } \\
\text { H. }\end{array}$} & \multirow[t]{4}{*}{$\begin{array}{l}\mathrm{Fe}_{1.957} \mathrm{O}_{3} \\
\text { Hematite }\end{array}$} & \multirow[t]{4}{*}{$\begin{array}{c}\mathrm{R}- \\
3 \mathrm{c}(167)\end{array}$} & $\begin{array}{l}\mathrm{a}=5.0041(2) \\
\mathrm{c}=13.6423(2)\end{array}$ & 25.7 & 51 \\
\hline 600 & & & & $\begin{array}{l}\mathrm{a}=5.0208(1) \\
\mathrm{c}=13.6717(2)\end{array}$ & 34.6 & 58 \\
\hline 700 & & & & $\begin{array}{l}\mathrm{a}=5.0120(1) \\
\mathrm{c}=13.6583(2)\end{array}$ & 23.3 & 69 \\
\hline 800 & & & & $\begin{array}{l}a=5.0051(2) \\
c=13.6664(2)\end{array}$ & 27.5 & 78 \\
\hline
\end{tabular}

According to XRD data, it is seen that an increase in the annealing temperature leads to a change in the phase composition of nanoparticles, as well as an increase in the average crystallite size and the degree of crystallinity. In the chemical synthesis of nanostructures, it is energetically advantageous to form compounds with a more simple crystal structure. This fact explains that during synthesis, nanoparticles of iron oxide with a face-centered cubic lattice of the Fd-3m (227) type group of spinel have been obtained, with a high content of iron vacancies in the structure, which explains the low degree of crystallinity. 
The initial sample is characterized by a Mossbauer spectrum with inhomogeneously broadened lines. The contributions of the integrated intensities of the partial spectra for the initial sample are characteristic of magnetite with a strongly disordered crystal structure. The value of the hyperfine magnetic field for the initial nanoparticles is in the range 440.81-465.97 kOe. That also confirms the assumption that the initial nanoparticles are magnetite particles with a disordered structure. The broadening and asymmetry of the extreme lines of the partial spectra, as well as the ratio of their intensities, also confirm the violation of the crystal structure, which is caused by the presence of impurities and cation vacancies in the lattice.

When thermal annealing of the initial sample with increasing annealing temperature, the values of the hyperfine magnetic field, quadrupole displacement and isomeric shift are observed. The results of changes in these values are presented in Table 2. According to the obtained data, the average values of the shift $\delta 1$ of the Mossbauer line and the quadrupole displacement $\varepsilon 1$ for the partial spectrum of the $\mathrm{Fe}_{1.957} \mathrm{O}_{3}$ characteristic for hematite with an annealing temperature higher than $400{ }^{\circ} \mathrm{C}$ practically do not change. The value of the hyperfine magnetic field for $\mathrm{Fe}_{1.957} \mathrm{O}_{3}$ increases, which indicates the ordering of the crystal structure.

Table 2. Data of changes in the values of the quadrupole displacement and isomer shift as a result of thermal annealing.

\begin{tabular}{|c|c|c|c|c|c|c|}
\hline $\mathbf{T},{ }^{\circ} \mathbf{C}$ & $\varepsilon_{1}, \mathrm{~mm} / \mathrm{s}$ & $\begin{array}{l}\mathrm{E} 2, \\
\mathrm{~mm} / \mathrm{s}\end{array}$ & $\varepsilon_{3}, \mathrm{~mm} / \mathrm{s}$ & $\delta_{1}, \mathrm{~mm} / \mathrm{s}$ & $\delta_{2}, \mathrm{~mm} / \mathrm{s}$ & $\delta_{3}, \mathrm{~mm} / \mathrm{s}$ \\
\hline Initial & $-0.038(8)$ & $0.028(8)$ & $0.257(50)$ & $0.197(10)$ & $0.686(14)$ & $0.549(60)$ \\
\hline 100 & - & $0.025(3)$ & $0.285(3)$ & - & $0.373(4)$ & $0.218(60)$ \\
\hline 200 & - & $0.002(6)$ & $0.268(50)$ & - & $0.322(6)$ & $0.215(90)$ \\
\hline 300 & $-0.11(1)$ & $\begin{array}{l}- \\
0.014(5)\end{array}$ & - & $0.378(5)$ & $0.320(4)$ & $0.475(10)$ \\
\hline 400 & $-0.1109(10)$ & $0.029(7)$ & $0.285(50)$ & $0.373(1)$ & $0.337(8)$ & $0.218(20)$ \\
\hline 500 & $-0.1081(10)$ & - & - & $0.369(1)$ & & - \\
\hline 600 & $-0.1072(20)$ & - & $0.285(50)$ & $0.372(2)$ & & $0.285(10)$ \\
\hline 700 & $-0.1042(10)$ & - & $0.285(30)$ & $0.371(7)$ & & $0.285(30)$ \\
\hline 800 & $-0.1052(20)$ & - & - & $0.372(2)$ & & - \\
\hline
\end{tabular}

According to the data of XRD and Mossbauer spectroscopy, the main phase transformations of the crystal structure are shown in Fig. 1.

Presented scheme shows three stages of phase transformations. The first initial stage, $100{ }^{\circ} \mathrm{C}$, is characterized by the appearance in the structure of two phases of $\mathrm{Fe}_{3} \mathrm{O}_{4}$ and $\beta$ $\mathrm{Fe}_{2} \mathrm{O}_{3}$ characteristic for magnetite. According to Mossbauer data, an increase in the annealing temperature leads to a decrease in the contribution of the doublet, which is characteristic of disordered $\mathrm{FeO}$. 


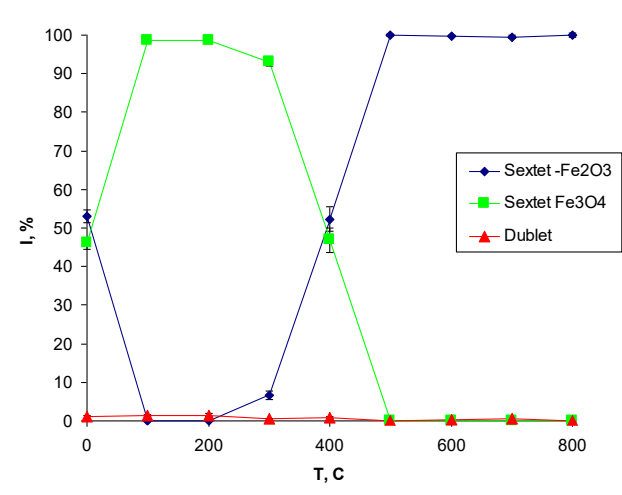

a)

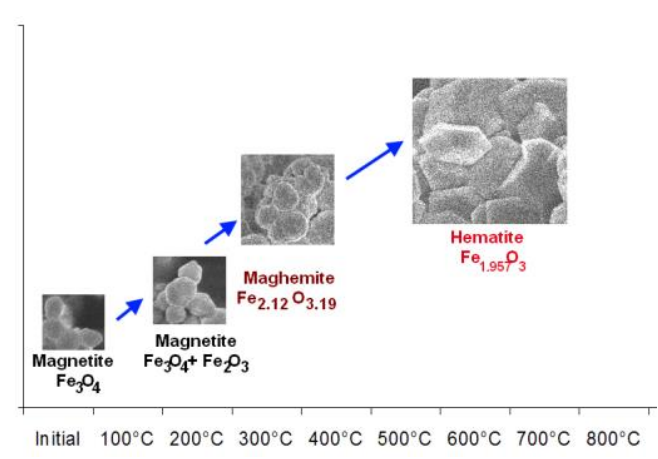

b)

Fig. 1. a) Graph of changes in the intensities of partial spectra during annealing; b) Phase transformation diagram as a function of the annealing temperature.

While the magnitude of the hyperfine magnetic field for the sextet increases, this indicates the ordering of the structure and annealing of the defects that have arisen during the synthesis. The second phase of phase transformations is typical for temperatures of 200 $400{ }^{\circ} \mathrm{C}$, which is characterized by a slight increase in the average size of nanoparticles and an increase in the degree of crystallinity. An increase in the annealing temperature above $200{ }^{\circ} \mathrm{C}$ leads to a rearrangement of the structure from $\mathrm{Fe}_{3} \mathrm{O}_{4}$ into the $\mathrm{Fe}_{2.12} \mathrm{O}_{3.19}$ structure characteristic of maghemite with the crystal lattice of the cubic syngony of the space group P4332 (122). At $300{ }^{\circ} \mathrm{C}$, according to the Mossbauer spectroscopy data, lines of partial spectra characteristic of $\mathrm{Fe}_{2} \mathrm{O}_{3}$ are observed. The subsequent increase in temperature leads to an increase in the contribution of the intensities of these lines to the structure. At $400{ }^{\circ} \mathrm{C}$, an equiprobable distribution of two contributions from $\mathrm{Fe}_{3} \mathrm{O}_{4}$ and $\mathrm{Fe}_{2} \mathrm{O}_{3}$ is observed, which indicates that under the given annealing conditions, it is possible to obtain nanoparticles of mixed type: maghemite and hematite. The third phase is typical for the formation of the hematite structure of $\mathrm{Fe}_{2} \mathrm{O}_{3}$, and begins at $500{ }^{\circ} \mathrm{C}$. In this case, a consistent increase in the annealing temperature leads to an increase in the value of the hyperfine magnetic field. This confirms the results of XRD analysis of the ordering of the structure and the reduction of defects in the crystal lattice. According to the data of XRD and Mossbauer spectroscopy, an increase in the annealing temperature, as well as the subsequent phase transformations of magnetite into maghemite and then to hematite, indicate an improvement in the structure and a decrease in microdistortions in the lattice as a result of annealing defects and vacancies. According to the data of Mossbauer spectroscopy at temperatures above $400{ }^{\circ} \mathrm{C}$, the lines of characteristic $\mathrm{FeO}$, which are characteristic for disordered iron oxide, are observed, which also confirms the improvement of the crystal structure of nanoparticles.

\section{References}

1. E. Veena Gopalan, K.A. Malini, G. Santhoshkumar. Nanoscale Res Lett, 5, 889 (2010)

2. L.G.Vivas, Y.P. Ivanov, D.G. Trabada, M.P. Proenca, Nanotechnology, 24, 105703 (2013)

3. J. Sarkar, G.G. Khan, A. Basumallick, Bull. Mater. Sci. 30, 271 (2007) 